This item was submitted to Loughborough's Research Repository by the author.

Items in Figshare are protected by copyright, with all rights reserved, unless otherwise indicated.

\title{
Airline competition in the British Isles
}

PLEASE CITE THE PUBLISHED VERSION

PUBLISHER

(c) Loughborough University

VERSION

VoR (Version of Record)

LICENCE

CC BY-NC-ND 4.0

REPOSITORY RECORD

Gaggero, Alberto A., and Claudio Piga. 2019. "Airline Competition in the British Isles". figshare. https://hdl.handle.net/2134/4232. 
This item was submitted to Loughborough's Institutional Repository (https://dspace.lboro.ac.uk/) by the author and is made available under the following Creative Commons Licence conditions.

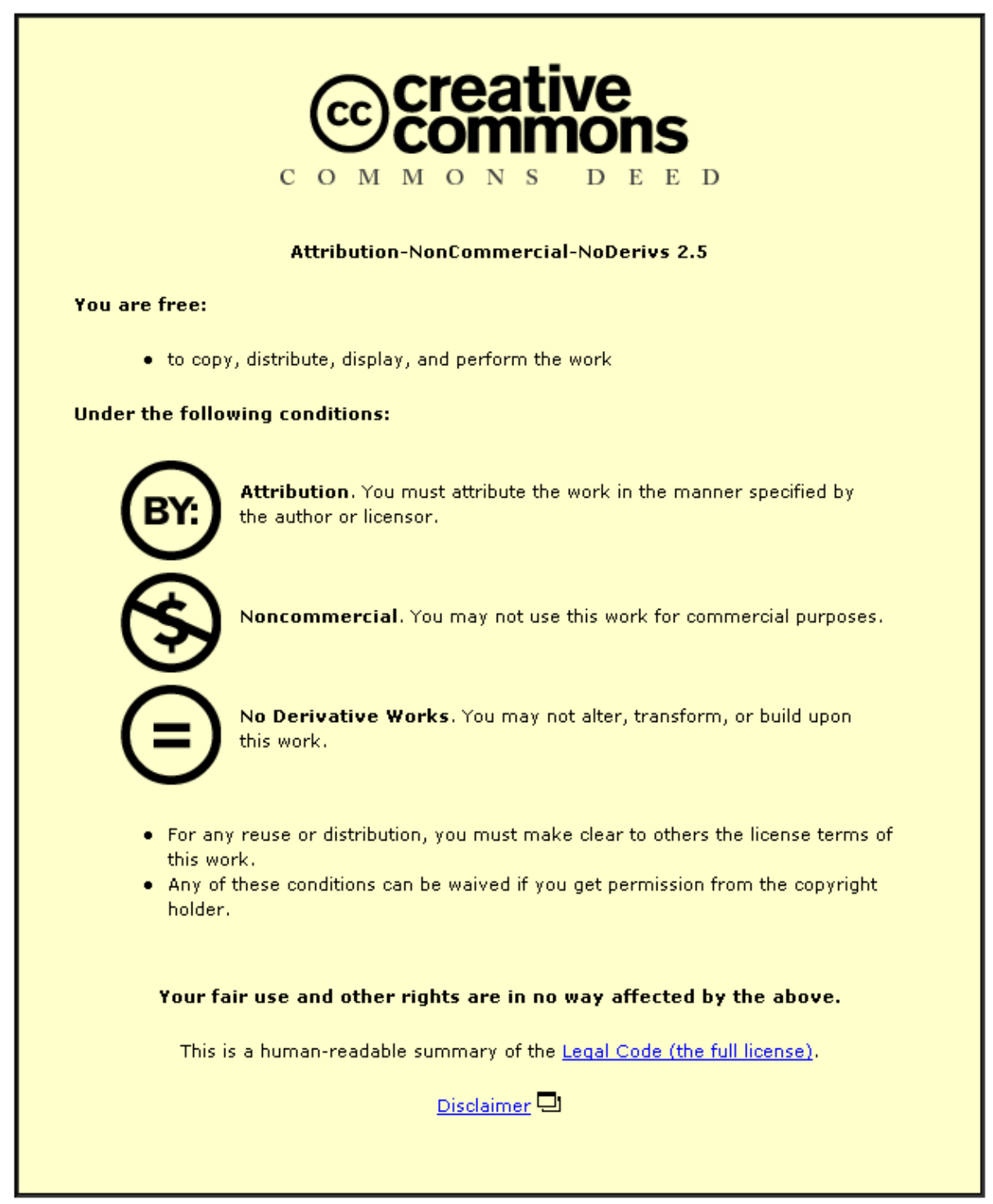

For the full text of this licence, please go to: http://creativecommons.org/licenses/by-nc-nd/2.5/ 
ISSN 1750-4171

\title{
DEPARTMENT OF ECONOMICS
}

\section{DISCUSSION PAPER SERIES}

Airline Competition in the British Isles

\author{
Alberto Gaggero \\ Claudio A. Piga
}

WP 2008 - 12

Dept Economics

Loughborough University

Loughborough

LE11 3TU United Kingdom

Tel: + 44 (0) 1509222701

Fax: + 44 (0) 1509223910

http://www.lboro.ac.uk/departments/ec

는 Loughborough University 


\title{
Airline Competition in the British Isles
}

\author{
Alberto A. Gaggero* \\ University of Essex \\ Claudio A. Piga ${ }^{\dagger}$ \\ Loughborough University
}

October 2008

\begin{abstract}
We study the relationship between pricing and market structure on the routes connecting the UK and the Republic of Ireland. Because in 2007 the European Commission prohibited the takeover of Aer Lingus by Ryanair, the analysis focuses on their pricing strategies in particular. We use an original dataset of fares posted on-line, which allows to control for the fares' intertemporal pattern for each specific flight and each carrier's specific yield management system. Our evidence supports the European Commission's view that the elimination of a competitor in the Irish airline market is likely to have harmful consequences for consumers.
\end{abstract}

Keywords: Ryanair, Aer Lingus, yield management, intertemporal pricing.

${ }^{*}$ Corresponding author. Department of Economics, University of Essex, Wivenhoe Park, Colchester CO4 3SQ, United Kingdom. Tel: +44 (0)1206 874468, fax: +44 (0)1206 872724, email: aagagg@essex.ac.uk.

${ }^{\dagger}$ Department of Economics, Epinal Way, Loughborough, LE11 3TU, UK; email: c.a.g.piga@lboro.ac.uk 


\section{Introduction}

Aer Lingus and Ryanair largely dominate the routes departing from the airports located in the Republic of Ireland. In October 2006, Ryanair launched a take-over bid for Aer Lingus. After an extensive investigation, in June 2007 the European Competition Commission decided to block the merger, arguing that the proposed acquisition would increase the market concentration and raise serious anti-competitive concerns (European Commission, 2007). For instance, out of the 35 intra-European routes operated by both parties, the acquisition would lead to monopoly in 22 routes, and to a dominant position with a joint market share of more than $60 \%$ on the remaining routes. Furthermore, the econometric evidence provided by the Commission indicates that the Ryanair's presence is associated with Aer Lingus charging around 7-8\% lower prices when considering city-pairs markets, and about 5\% lower prices when considering airport-pairs. ${ }^{1}$ Aer Lingus prices therefore appear to be constrained by competition from Ryanair. Although the evidence supporting the related notion of Aer Lingus exerting a competitive constraint on Ryanair's prices is weak, the European Commission concluded that the two carriers were close competitors. Finally, in addition to the elimination of actual competition, the analysis in European Commission (2007) also points out to other likely negative impacts: lack of incentive to develop new routes; elimination of potential competition, in particular with regards to either parties entering routes where the other is already present; unlikely entry by a third party, because the enhanced position of the merged entities would make it difficult for a new entrant to establish a viable competitive presence.

Building on a dataset of on-line posted fares, where for each flight fares are tracked over about a two months' period, we pursue two main objectives. First, we look at whether, in some overlapping routes, fares posted by the one of the carriers are consistently higher or lower than those posted by the other. Thus, by looking at fares posted at different points in time, our approach complements the

\footnotetext{
${ }^{1}$ A city-pair (e.g., London and Dublin) generally includes more than one route, each identified by a unique airport-pair combination (e.g., London Heathrow/Dublin and London Stansted/Dublin).
} 
analysis in European Commission (2007), where average fares are used. According to Borenstein and Rose (2007, p.30), business-model experimentation, in pricing, logistics, competitive strategies and organizational form has been a key feature of the US airline industry following deregulation. The coexistence of alternative business models, such as the established full-service model based on the hub-andspoke system and the recent low-cost model based on the point-to-point service, is a recent example (Alderighi et al., 2004). In the present setting, we focus on the role of revenue management systems, which constitute an important managerial and strategic tool because they enable a better alignment of the evolution of actual demand relative to forecast demand for individual flights. They are also used to implement peak-load pricing and third-degree price discrimination (Dana, 1999). We suggest that the way the two carriers tackle their revenue management problems may be reflected to a large extent in the inter-temporal profiles of their fares. Detecting differences in such profiles has important implications on the way the markets are segmented and therefore on the welfare evaluation of the takeover.

Second, we conduct a panel data analysis on the routes connecting the Republic of Ireland to the United Kingdom to evaluate the relationship between pricing and market structure, as well as the extent to which the absence of one of the carriers in a route affects the price levels of the other. Relative to the methodology employed by the European Commission, we address the simultaneity problem linking price and market structure by adopting Instrumental Variable techniques with the instruments proposed in Borenstein (1989) and previously unused variables. In our analysis, market structure measures are defined both at the route and the city-pair level. Such a distinction between relevant market definitions may again be important to assess the competitive effects of a proposed takeover. Indeed, a monopolistic route may be subject to strong competitive forces when it represents a product which can be easily substituted with many other routes in the same city-pair. 


\section{The data set}

The analysis relies on two main data sets, one containing primary data on posted fares, the other providing market structure measures derived from secondary data obtained by the UK Civil Aviation Authority (CAA).

All the fares were obtained from the internet using a web spider, which accessed the web-sites of the low-cost carriers (LCCs) included in the sample (Bmibaby, Mytravellite and Ryanair), and retrieved the fares of the Full Service Carriers, namely Aer Lingus and British Airways, from an on-line travel agent, Opodo. $^{2}$ For each day between 1 June 2003 and 31 December 2004 and for each flight code, the spider collected all the posted fares that a hypothetical consumer would pay if she booked her ticket 1, 4, 7, 10, 14, 21, 28, 35, 42, 49, 56, 63 and 70 days $^{3}$ before the departure day. ${ }^{4}$ We will refer to these dates as "booking days".

LCCs price each leg independently and the retrieved fares refer to a single oneway ticket. Fare data for the Full Service Carriers (FSCs), instead, reflect a more sophisticated yield management technique that usually makes it uneconomical for the consumers to buy each leg independently. ${ }^{5}$ Therefore, for the FSCs the spider collected round-trip fares, which could be considered more representative of the actual fare pattern observed by consumers. Furthermore, because the LCCs' fares do not include such restrictions as Saturday night stay-over, the spider was programmed to have the return leg scheduled one week after the outgoing flight. To make a FSCs round trip fare comparable with a LCC one-way fare, we follow the traditional approach in the literature to halve the former (Borenstein, 1989; Borenstein and Rose, 1994). Before we do so, we deal with the fact that each first leg could be combined with different return flights, each differing by departure

\footnotetext{
${ }^{2}$ See www.opodo.co.uk, which is owned and managed by Aer Lingus, Air France, Alitalia, Austrian Airlines, British Airways, Finnair, Iberia, KLM, Lufthansa, and the global distribution system Amadeus. Thus, fares listed on Opodo represent the official prices of each airline; although Opodo may not report promotional offers that an airline may post on its own website.

${ }^{3}$ For Aer Lingus and British Airways the series reduces to 7, 10, 14, 21, 28, 35, 42, 49 and 56.

${ }^{4}$ See Piga and Bachis (2007), where this same time pattern is used.

${ }^{5}$ FSCs normally price a round-trip ticket cheaper than two separate one-way tickets, so that consumers have the incentives to purchase round trip tickets; the airline is thus able to implement third-degree price discrimination (Giaume and Guillou, 2004).
} 
time. The spider retrieved all these possible combinations of fares, which we use to construct a daily average round trip fare.

The UK CAA provided census monthly data for the full set of flights operated between the UK and Ireland during the period June 2003 - December 2004. This dataset contains information on the frequency, the number of passengers and the available seat capacity of each flight code, which were used to construct various market structure variables. Finally, routes' distance were taken from the World Airport Codes' web site, http://www.world-airport-codes.com.

\section{$3 \quad$ Intertemporal Pricing}

As discussed in the Introduction, to shed light on the pricing activities of both Aer Lingus and Ryanair this paper focuses on the routes connecting the Republic of Ireland with the United Kingdom. This is an extremely relevant market because, in the period June 2002 - June 2005, the two carriers accounted for about $63 \%$ to $70 \%$ of the traffic between these two countries, although they were present in about $42 \%$ of routes or city-pairs. ${ }^{6}$ Figure 1 illustrates the temporal fare pattern in the three routes in our price sample, namely Birmingham-Dublin (BHX-DUB), Edinburgh-Dublin (EDI-DUB) and Manchester-Dublin (MAN-DUB), that are both served by Aer Lingus and Ryanair.

In line with the evidence in Piga and Bachis (2007) showing that the FSCs tend to exhibit a flatter temporal fare pattern than LCCs, Aer Lingus fares are on average above those of Ryanair for early booking days, but the steep profile of the latter's fares suggests that the gap between the two carriers' fares closes rapidly as the date of departure approaches and hence indicates that Ryanair's fares may be higher just a few days before the take-off. ${ }^{7}$

To further investigate the nature of the price competition among the the carriers, we try to evaluate whether one of the carriers consistently prices above or below the other. To do so, we take into account that flights on the same

\footnotetext{
${ }^{6}$ Our price sample covers about a third of all the routes between the two countries.

${ }^{7}$ Unfortunately, the spider could only retrieve the fares from the on-line travel agent up to seven days before departure.
} 
route may be differentiated with respect to the time of departure. Therefore, we divide a day into four parts and cluster the flights accordingly: Morning ( $\mathrm{h}$ 6-10), Day (h 10-14), Afternoon (h 14-18) and Evening (h 18-24). ${ }^{8}$ For each pair matching flights between Aer Lingus and Ryanair, table 1 reports the proportion of matched price observations where Ryanair is more expensive than Aer Lingus. ${ }^{9}$ Overall Ryanair is cheaper than Aer Lingus, especially on morning flights. More importantly, the analysis based on the inter-temporal price dimension reveals a pattern consistent with the evidence in Figure 1. Indeed, the likelihood of Ryanair's fare being higher than its competitor's increases as the day of departure nears.

However, such a finding may be driven by small differences in the two fares and does not take account of differences in on-board services; in Table 2 a similar analysis is conducted, although a flight's fare is considered higher only if it exceeds the competitor's fare by at least $£ 10$. About $40 \%$ of the observations fall into the indifference band, resulting in lower dispersion than in table 1. Ryanair's fares are more likely to be significantly higher than its competitor's if a flight is operated in the evening and booked only a few days before departure. Table 1 confirms that Ryanair's price advantage shrinks as the departure date approaches.

To sum up, the evidence suggests that during the sample period, the two carriers followed a different revenue management approach. As far as the takeover's welfare implications are concerned, eliminating one carrier may result in the acquiring company's revenue management being used exclusively (Dobson and Piga, 2008). More specifically, the analysis seems to indicate that the takeover would not have affected early bookers but it could have been particularly detrimental to Aer Lingus' late booking passengers; while not included in European Commission (2007), this result supports the decision to block the merger.

\footnotetext{
${ }^{8}$ Note that for aviation rules imposed by the Government, there are no flights taking off between midnight and 6 am.

${ }^{9}$ The analysis is based on 65 flight codes: 37 operated by Aer Lingus and 28 operated by Ryanair, for a total of 21,204 matching observations.
} 


\section{Econometric model}

To evaluate whether the presence of one carrier (e.g., Ryanair) constrains the pricing of the other (Aer Lingus), the European Commission (2007) regressed the average price on a route of the latter carrier against a set of explanatory variables, including a dummy for the competitor's presence on the route and other market structure indicators (See European Commission, 2007, p. 469-477). That is, the analysis is restricted to the prices of the carriers under study.

In our econometric approach we adopt a different strategy because we pool all the companies that operate in the markets under consideration. As in European Commission (2007), we define markets as either an airport-pair (i.e., route) or as a city-pair. Given the differentiated nature of airlines' products, using the route as the relevant market concept is a sound econometric strategy only if each route is not a viable substitute for travelers. When consumers perceive two routes belonging to the same city-pair as, to some extent, substitutes, using market structure variables defined at the city-pair level produces more reliable estimates. Since we cannot determine the extent to which the markets under consideration are differentiated, we estimate both types of models.

The econometric model we use to study the relationship between pricing and market structure is expressed by the following equation:

$$
\begin{aligned}
\ln P_{i t}= & \alpha_{i}+\mu_{1} \mathrm{MS}_{i}+\mu_{2} \mathrm{HHI}_{i}+\mu_{3} \text { onlyEI }_{i}+\mu_{4} \text { onlyFR }_{i}+ \\
& +\theta_{1} \text { Departime }_{i}+\theta_{2} \text { Arr } \text { Dep }_{i}+\theta_{3} \text { Bday }_{i t}+\rho_{1} \ln (\text { Distance })_{i}+ \\
& +\pi_{1} \mathrm{Xmas}_{i}+\pi_{2} \text { Easter }_{i}+\pi_{3} \text { StPatrick }_{i}+ \\
& +\delta_{1} \text { Company }_{i}+\delta_{2} \text { Month }_{i}+\delta_{3} \text { DayWeek }_{i}+\varepsilon_{i t}
\end{aligned}
$$

where $\ln P_{i t}$ denotes the $\log$ of the weekly mean fare for each flight code $i{ }^{10}$ In order to track the evolution of each flight's fare over time, the subscript $t$ denotes the booking days. ${ }^{11}$ The regressors are grouped into different categories:

\footnotetext{
${ }^{10}$ Each fare is net of airport taxes and surcharges.

${ }^{11} \mathrm{So}$, for example, the flight code FR507 departing on 1 June 2003 is considered as one panel observed at booking days $1,4,7,10,14,21,28,35,42,49,56,63$ and 70 .
} 
(i) $\mu$ coefficients indicate market structure variables, (ii) $\theta$ coefficients refer to flight and fare characteristics, (iii) $\rho$ coefficients denote the cost factors, (iv) $\pi$ coefficients account for demand factors, $(\mathrm{v}) \delta$ coefficients correspond to a set of additional dummies. Finally $\varepsilon_{i t}$ is the white noise regression error, and $\alpha_{i}$ is a random, panel specific, intercept.

The market structure variables on which we focus the attention are defined as follows:

- Route/City Market Share (MS), calculated using the number of flights operated by a company in either a route or a city-pair over the total number of flights; ${ }^{12}$

- Route/City Herfindahl Index (HHI), calculated from the market shares described above;

- onlyEI: dummy equals one if Aer Lingus operates and Ryanair does not operate on the observed route. ${ }^{13}$

- onlyFR: dummy equals one if Ryanair operates and Aer Lingus does not operate on the observed route/city-pair.

Fares are expected to be positively related to both MS and HHI. The coefficients of onlyEI and onlyFR, if positive, should provide insights to the extent by which the presence of a competitor constitutes a constraint to the pricing activity of the other. A definition of the other control variables listed in equation (1) can be found in the Appendix.

Another point of departure of the present analysis from the one conducted by European Commission (2007) lies in the use of Instrumental Variable methods to account for the potential correlation of the market structure variables with

\footnotetext{
${ }^{12}$ Number of flights and number of passengers are highly correlated variables. We use the former because it is decided by the carriers well in advance of the traveling period, and is therefore to be considered as a pre-determined variable which is not simultaneously chosen with price.

${ }^{13}$ Note that we do not have any case in which Aer Lingus does not face Ryanair on a city-pair and therefore onlyEI cannot be defined at the city-pair level.
} 
the error term $\varepsilon_{i t}$ (i.e., the fact that the market structure variables may be simultaneously determined with price. ${ }^{14}$ ) Following a traditional approach in the literature, the Market Shares and the Herfindhal Indices are instrumented using the variables adopted in Borenstein (1989) and Borenstein and Rose (1994). More precisely, Market Share is instrumented by the ratio between the observed carrier's geometric mean of enplanements at the endpoints of a route and the sum across all carriers of the geometric mean of each carrier's enplanements at the endpoints. The Herfindhal Index is instrumented with a quasi-HHI, denoted as I_HHI, that sums together the fitted value of the observed carrier's MS, $\widehat{\mathrm{MS}}$ (obtained from an auxiliary regression of MS on its instrument and all the exogenous right-hand side variables), with the re-scaled HHI of the traffic that is left to be divided among other carriers. In formula: I_HHI $=\widehat{\mathrm{MS}}^{2}+\left(\mathrm{HHI}-\mathrm{HMS}^{2}\right) \frac{(1-\widehat{\mathrm{MS}})^{2}}{(1-\mathrm{MS})^{2}}$.

We construct our own set of instruments for onlyEI and onlyFR: they are respectively defined as the sum of the number of flights operated by the competitor at each endpoints of the route or city. For instance, for only $F R$ we use the sum of all Aer Lingus' flights landing at each endpoints of a route/city-pair. The identifying criterion draws from the assumption used in Berry (1992), Morrison and Winston (1990) and Goolsbee and Syverson (2008) that entry in a route is more likely if a competitor already operates from at least one of the route's endpoints.

\section{Results}

Equation (1) is estimated using the Random Effect (RE) estimator. Since the variables of interest are MS, HHI and the two dummies onlyEI and onlyFR, these are included one at the time (with the exception of the joint use of onlyEI and onlyFR) in our regressions to avoid collinearity problems. Furthermore, because each of them captures one specific feature of the market, Tables 3 and

\footnotetext{
${ }^{14}$ The Commission acknowledges the concern and "... tested a number of candidate instruments included in the data set, such as intra-route frequency rank, own costs or own total frequencies at destination airport. However all these instruments turned out to have very poor properties." (European Commission, 2007, page 485).
} 
4 report the estimates of equation (1) when markets are defined respectively as routes or city-pairs.

As far as the variables controlling for market structure are concerned, the two tables present striking differences. When the market share and the Herfindhal index are defined at the route level, their coefficients are both negative, but become positive (and produce a larger economic effect in absolute terms) when city-pair markets are considered instead. Such a difference may be driven by the poor performance of the instruments, which at the route level may be not able to vary sufficiently to purge the effects that unobserved variables have on both fares and market shares (or the HHI). For instance, small potential demand at the route level may induce both high levels of route concentration due to the high fixed costs of operating in a route and also low prices (hence the negative coefficients in Table 3). A firm that is a monopolist in a small route cannot mark fares up if it faces competition from other carriers operating in other routes of the same city-pair (hence the positive correlation between low concentration and low fares). Considering that the city-pair coefficients also produce a better fit for the data $\left(R^{2}\right.$ is about 0.34 while it is about 0.29 when markets are defined at the route level), we conclude that high market shares and high levels of market concentrations appear to be positively associated with observed fares, to the extent that their increase by $10 \%$ leads to fares that are, respectively, about $2.6 \%$ and $3.5 \%$ higher. Further support to the hypothesis that lack of competition is associated with the exercise of some degree of market power in the British-Irish airline market is found by looking at the coefficient of the dummy only $F R$, which at the city-pair level is equal to 0.16. This implies that when Ryanair does not compete with Aer Lingus on the same city-pair, its fares are about $17.4 \%$ higher. $^{15}$

Always with regards to the coefficients in Table 4, we set Ryanair's company

${ }^{15}$ The percentage numbers stem from the formula in Wooldridge (2005):

$$
100 *[\exp (\widehat{\beta})-1]
$$

which calculates the marginal effect in percentage terms of a dummy variable when the dependent variable is expressed in logarithmic form; $\hat{\beta}$ is the estimated coefficient of the dummy variable. 
dummy as base dummy. Therefore, the variable denoted as "Aer Lingus" measures to what extent Aer Lingus' fares differ in magnitude from Ryanair's ones. The positive and statistically significant coefficient indicates that Aer Lingus consistently prices higher than Ryanair, on average by $31 \%$.

All the remaining regressors behave as expected. Distance, which is positive and statistically significant, proves to be a good approximation of operating, and fuel in particular, costs. Indeed taking the log captures the economies of scale of operating longer routes, since landing and take-off are fuel-intensive operations.

The holiday dummies are positive and statistically significant, indicating that flying during a holiday period is on average more expensive. Note also that the increasing magnitude of the coefficients from StPatrick to Xmas is exactly in line with what one would expect: the magnitude of coefficients seems to accord with the relative importance of each festivity. Indeed, the largest price hikes are observed during Christmas, followed by Easter and St Patrick.

The coefficients of the booking day dummies ("Booking Day 4" to "Booking Day 70") define an interesting, albeit largely expected, pattern. With the "Booking Day 1" as the omitted category, the other twelve booking day dummies are negative and statistically significant at $1 \%$ level, indicating that the early bookers on average obtain better deals. Note also that the coefficient on these dummies remains stable around -1.6 until the last month before the departure, then it smoothly declines as the departure day approaches. The evidence is therefore consistent with the view that fares increase monotonically over time. Using a larger sample, Piga and Bachis (2007) show how this property generally holds when fares are averaged over a predetermined sample period (say, a week or month), but it is likely to be violated when one investigates the fares of individual flights over time. That is, it is often observed that, for the same flight, fares posted between, say, one month and twenty days from departure may be lower than those posted prior to that period. Generally, however, very late fares (those posted within a week of departure) are the highest, in order to signal the carriers' commitment to high fares in the days immediately preceding a flight's take-off, and thus discourage strategic buyers' behavior. 


\section{Conclusion}

The analysis in Dobson and Piga (2008) indicates that Ryanair's successful attempt in 2003 to take over another low-cost carrier, Buzz, generally led to lower fares, increased flight frequency on the acquired routes and higher quality in the form of improved punctuality performance, and suggests that it may have therefore benefitted consumers. Nonetheless, in 2007 the European Commission, after the extensive investigation carried out by its competition authorities, decided to block the takeover by Ryanair on the other main player in the Irish airline market, Aer Lingus. The European Commission's concerns about the increased market power of the acquiring firm and particularly diminished choice for Irish consumers appear to have overridden the possible opposing benefits from Ryanair's application of its highly successful low-cost business model, which could have been applied for the first time to the intercontinental routes that Aer Lingus operates. $^{16}$

The evidence in this paper generally lends support to the European Commission's decision. First, we show that the elimination of a competitor when carriers follow different revenue management methods is likely to harm certain segments of consumers (in this particular case, those with uncertain demand whose need to book a flight is generally revealed just a few days prior to a flight's departure).

Second, the econometric exercise with instrumental variables reveals that fares are higher in the British-Irish concentrated city-pair markets, or in markets with firms with high market shares. Considering that in many routes the takeover would have led to a pure monopolistic structure at the route level, and therefore to an increase of concentration at the city-pair level, it is not unrealistic to assume that the takeover could have exacerbated the exercise of market power highlighted by our analysis.

Third, in line with the analysis in European Commission (2007), we do find that the presence of one carrier constrains the pricing behavior of the other.

\footnotetext{
${ }^{16}$ A distinctive difference between the two target companies, Aer Lingus and Buzz, is that the former has strongly opposed the takeover, while the latter was consensually sold by its holding company, KLM.
} 
With the coming of age of the European liberalization process which has radically changed the configuration of the airline industry by favoring the emergence of the Low-Cost Carriers, the consolidation of some legacy carriers (think of the Air France-KLM and the BA-Iberia mergers) and the collapse of others (Alitalia, Sabena, Swiss Air), it is not unlikely that the two main players in the Irish airline market, Ryanair and Aer Lingus, will find themselves involved in other takeover attempts, both among themselves or other carriers. More takeover attempts may be simply driven by the need to cut costs, intensify scale and density economies and manage the high, and permanent, volatility of fuel prices. Our analysis suggests that to be equipped to provide effective evaluations of a merger bid's effects, a systematic collection of fares and market structure information is essential. Therefore, an attempt to construct a fares' database at the European level similar to the one produced by the U.S. Department of Transportation (the Airline Origin and Destination Survey DB1B) should be given consideration by policymakers. ${ }^{17}$

\section{Acknowledgements}

The authors are grateful for the useful comments provided by the participants of both the ATRS 2008 conference in Athens and the CCRP workshop in London. We thank Alison Booth, Severin Borenstein, Stephen Jenkins, João Santos Silva, and George Symeonidis for their feedback. Piga acknowledges receipt of the British Academy Research Grants LRG-35378 and SG-45975.

\footnotetext{
${ }^{17}$ See Peters (2006) for an evaluation of mergers in the U.S. airline market that uses the DB1B data.
} 


\section{References}

[1] Alderighi M., A. Cento, P. Nijkamp and P. Rietveld (2004), "Network competition: the coexistence of hub-and-spoke and point-to-point systems" , Journal of Air Transport Management, 11(5), 328-334.

[2] Berry S. (1992), "Estimation of a model of entry in the airline industry" , Econometrica 60(4), 889-917

[3] Borenstein S. (1989), "Hubs and high fares: dominance and market power in the US airline industry" RAND Journal of Economics, 20(3), 344-365

[4] Borenstein S., and N. Rose (1994), "Competition and Price Dispersion in the U.S. Airline Industry" , Journal of Political Economy102(4), 653-683

[5] Borenstein, S., and N. Rose (2007), "How Airline Markets Work, or Do They?; Regulatory Reform in the Airline Industry" http://www.nber.org/books/econ-reg/borenstein-rose3-30-07.pdf.

[6] Dana, J. (1999), "Equilibrium price dispersion under demand uncertainty: the roles of costly capacity and market structure" Rand Journal of Economics, 30(4), 632-660

[7] Dobson, P. W. and C. A. Piga (2008), "Mergers and Business Model Assimilation: Evidence from Low-Cost Airline Takeovers " , RePEc Discussion Paper Series, N. 2008-12, Loughborough University, UK, www.lboro.ac.uk/departments/ec/RePEc/lbo/lbowps/LCCmergers.pdf

[8] European Commission (2007), "Case No COMP/M. 4439 - Ryanair / Aer Lingus" downloadable at http://ec.europa.eu/comm/competition/mergers/cases/decisions/m4439_ 20070627_20610_en.pdf

[9] Giaume, S. and S. Guillou (2004), "Price Discrimination and Concentration in European airline markets ", Journal of Air Transport Management, 10, 305-310. 
[10] Goolsbee A. and C. Syverson (2008), "How do Incumbents Respond to the Threat of Entry? Evidence from Major Airlines", Quarterly journal of Economics, 123(4), 16111633.

[11] Morrison S. and C. Winston (1990), "The Dynamics of Airline Pricing and. Competition", American Economic Review, 80(2) pp. 389-393

[12] Peters, C. (2006), "Evaluating the Performance of Merger Simulation: Evidence from the U.S. Airline Industry", Journal of Law and Economics, 49, 627-649.

[13] Piga, C. A. and E. Bachis. (2007). "Pricing Strategies by European Traditional and Low-Cost Airlines: or, When Is It The Best Time To Book On Line?", in Darin Lee (ed.), Advances in Airline Economics, Volume 2: The Economics of Airline Institutions, Operations and Marketing, Elsevier: Amsterdam, ch. 10, 319-344.

[14] Wooldridge J. (2005), "Introductory Econometrics: A Modern Approach" $\left(3^{\text {rd }}\right.$ Ed), South-Western:Thompson Learning 


\section{Appendix: description of the independent vari- ables}

\section{VARIABLE DEFINITION}

\begin{tabular}{ll}
\hline \hline Departime & Time of a flight's take-off, decoded into four dummies: \\
& Morning (h 6-10), Mday (h 10-14), Afternoon (h 14-18), \\
& Evening (h 18-24). Morning is the base category. \\
\hline Arr/Dep & dummy equal one if the itinerary originates in UK and \\
& zero if it originates in the Republic of Ireland. \\
\hline Booking day & $\begin{array}{l}\text { number of days separating the departure date from } \\
\text { the day the fare was retrieved. It assumes values }\end{array}$ \\
& $\begin{array}{l}\text { 1, } 4,7,10,14,21,28,35,42,49,56,63 \text { and } 70 \\
\text { and is decoded with a set of dummy variables, one for each } \\
\text { booking day category. The base dummy is } 1 \text { day. }\end{array}$ \\
\hline ln(Distance) & $\begin{array}{l}\text { logarithm of the distance between the two endpoints } \\
\text { of a route in } 100 \text { km. }\end{array}$ \\
\hline Xmas & dummy variable equal to one if the flight is operated \\
& during the weeks of Xmas/New Year, and zero otherwise. \\
\hline Easter & dummy variable equals to one if the flight is operated \\
& during the week of Easter, and zero otherwise. \\
\hline StPatrick & $\begin{array}{l}\text { dummy variable equals to one if the flight is operated } \\
\text { during the week of St. Patrick's festival, and zero otherwise. }\end{array}$ \\
\hline Company & set of airline dummies, Ryanair is the omitted company. \\
\hline Month & set of month dummies \\
\hline DayWeek & set of day-of-the-week dummies. \\
\hline
\end{tabular}


Table 1: Share of Ryanair's fares that are higher than Aer Lingus'

\begin{tabular}{lcc|cc|cc}
\hline & \multicolumn{2}{c}{ BHX-DUB } & \multicolumn{2}{c}{ EDI-DUB } & \multicolumn{2}{c}{ MAN-DUB } \\
& Frequency & Obs. & Frequency & Obs. & Frequency & Obs. \\
\hline \hline Departure Time & & & & & & \\
Morning & $27.8 \%$ & 2,605 & $29.8 \%$ & 1,317 & $15.7 \%$ & 2,421 \\
Day & $37.4 \%$ & 2,529 & & & $30.8 \%$ & 2,224 \\
Afternoon & $25.0 \%$ & 895 & $54.2 \%$ & 419 & $20.3 \%$ & 2,263 \\
Evening & $46.1 \%$ & 2,629 & $46.2 \%$ & 1,566 & $25.0 \%$ & 2,335 \\
\hline Booking Day & & & & & & \\
56 days & $31.7 \%$ & 520 & $45.3 \%$ & 202 & $21.6 \%$ & 515 \\
49 days & $26.1 \%$ & 1,088 & $57.9 \%$ & 446 & $21.4 \%$ & 1,142 \\
42 days & $27.6 \%$ & 1,139 & $42.1 \%$ & 461 & $20.3 \%$ & 1,208 \\
35 days & $30.5 \%$ & 1,173 & $39.1 \%$ & 461 & $18.9 \%$ & 1,220 \\
28 days & $32.1 \%$ & 1,211 & $37.5 \%$ & 459 & $16.8 \%$ & 1,265 \\
1 days & $35.9 \%$ & 1,189 & $35.4 \%$ & 444 & $19.8 \%$ & 1,309 \\
10 days & $43.5 \%$ & 1,215 & $38.1 \%$ & 428 & $25.7 \%$ & 1,315 \\
7 days & $54.5 \%$ & 571 & $43.1 \%$ & 204 & $32.1 \%$ & 633 \\
\hline & $59.4 \%$ & 552 & $46.5 \%$ & 198 & $41.8 \%$ & 636 \\
\hline Total & & & & & & \\
\hline
\end{tabular}


Table 2: Likelihood that Ryanair's fares differ by at least £10 from Aer Lingus'

\begin{tabular}{|c|c|c|c|c|}
\hline & $\begin{array}{c}\text { Difference } \\
\text { in fares } \\
\text { within } £ 10\end{array}$ & $\begin{array}{c}\text { FR fares } \\
\text { at least } £ 10 \\
\text { more than EI }\end{array}$ & $\begin{array}{c}\text { EI fares } \\
\text { at least } £ 10 \\
\text { more than FR }\end{array}$ & $\begin{array}{c}\text { Number } \\
\text { of } \\
\text { Obs. }\end{array}$ \\
\hline \multicolumn{5}{|l|}{ Departure Time } \\
\hline Morning & $36.6 \%$ & $10.3 \%$ & $53.1 \%$ & 6,343 \\
\hline Day & $44.8 \%$ & $13.8 \%$ & $41.4 \%$ & 4,754 \\
\hline Afternoon & $38.0 \%$ & $11.2 \%$ & $50.8 \%$ & 3,577 \\
\hline Evening & $39.1 \%$ & $21.2 \%$ & $39.7 \%$ & 6,530 \\
\hline \multicolumn{5}{|l|}{ Booking Day } \\
\hline 56 days & $36.6 \%$ & $14.6 \%$ & $48.8 \%$ & 1,237 \\
\hline 49 days & $39.7 \%$ & $11.3 \%$ & $49.0 \%$ & 2,676 \\
\hline 42 days & $39.2 \%$ & $11.6 \%$ & $49.2 \%$ & 2,808 \\
\hline 35 days & $40.9 \%$ & $9.9 \%$ & $49.2 \%$ & 2,854 \\
\hline 28 days & $39.4 \%$ & $11.2 \%$ & $49.3 \%$ & 2,935 \\
\hline 21 days & $39.0 \%$ & $13.3 \%$ & $47.8 \%$ & 2,942 \\
\hline 14 days & $38.6 \%$ & $18.3 \%$ & $43.2 \%$ & 2,958 \\
\hline 10 days & $42.0 \%$ & $23.5 \%$ & $34.5 \%$ & 1,408 \\
\hline 7 days & $39.2 \%$ & $29.7 \%$ & $31.2 \%$ & 1,386 \\
\hline Total & $39.4 \%$ & $14.6 \%$ & $46.0 \%$ & 21,204 \\
\hline
\end{tabular}

EI and FR are short for Aer Lingus and Ryanair respectively. 
Table 3: Instrumental Variable Estimates with markets defined at route level. Dependent Variable: Log of mean weekly fares

\begin{tabular}{lrrr}
\hline & Model 1 & Model 2 & Model 3 \\
\hline \hline Route Market Share & -0.21 & & \\
Route Herfindhal Index & & -0.07 & \\
onlyEI & & & 0.68 \\
onlyFR & & & -0.23 \\
log(Distance) & 0.60 & 0.56 & 0.39 \\
Aer Lingus & 0.65 & 0.67 & 0.16 \\
Booking Day 4 & -0.56 & -0.56 & -0.56 \\
Booking Day 7 & -1.32 & -1.32 & -1.32 \\
Booking Day 10 & -1.46 & -1.46 & -1.46 \\
Booking Day 14 & -1.87 & -1.87 & -1.87 \\
Booking Day 21 & -2.07 & -2.07 & -2.07 \\
Booking Day 28 & -2.11 & -2.11 & -2.11 \\
Booking Day 35 & -2.02 & -2.02 & -2.02 \\
Booking Day 42 & -1.98 & -1.98 & -1.98 \\
Booking Day 49 & -2.04 & -2.04 & -2.04 \\
Booking Day 56 & -2.09 & -2.09 & -2.09 \\
Booking Day 63 & -2.07 & -2.07 & -2.07 \\
Booking Day 70 & -2.00 & -2.00 & -2.01 \\
Xmas & 0.84 & 0.84 & 0.84 \\
Easter & 0.47 & 0.47 & 0.47 \\
StPatrick & 0.19 & 0.19 & 0.18 \\
& & & \\
R & 0.29 & 0.29 & 0.27 \\
Observations & 135,468 & 135,468 & 135,468 \\
\hline
\end{tabular}

Note: All the variables described in the Appendix were included, but are not reported to save space. All coefficients statistically significant at $1 \%$ level. 
Table 4: Instrumental Variable Estimates with markets defined at city-pair level. Dependent Variable: Log of mean weekly fares

\begin{tabular}{lrrr}
\hline & Model 1 & Model 2 & Model 3 \\
\hline \hline $\begin{array}{l}\text { City Market Share } \\
\text { City Herfindhal Index }\end{array}$ & 0.26 & & \\
onlyFR City & & 0.35 & \\
log(Distance) & 0.30 & 0.31 & 0.16 \\
Aer Lingus & 0.28 & 0.27 & 0.26 \\
Booking Day 4 & -0.42 & -0.42 & -0.42 \\
Booking Day 7 & -0.95 & -0.95 & -0.95 \\
Booking Day 10 & -1.09 & -1.09 & -1.09 \\
Booking Day 14 & -1.34 & -1.34 & -1.34 \\
Booking Day 21 & -1.52 & -1.52 & -1.52 \\
Booking Day 28 & -1.59 & -1.59 & -1.59 \\
Booking Day 35 & -1.59 & -1.59 & -1.59 \\
Booking Day 42 & -1.59 & -1.59 & -1.59 \\
Booking Day 49 & -1.61 & -1.61 & -1.61 \\
Booking Day 56 & -1.65 & -1.65 & -1.65 \\
Booking Day 63 & -1.66 & -1.66 & -1.66 \\
Booking Day 70 & -1.64 & -1.64 & -1.64 \\
Xmas & 0.55 & 0.55 & 0.54 \\
Easter & 0.25 & 0.25 & 0.25 \\
StPatrick & 0.14 & 0.14 & 0.14 \\
& & & \\
R & 0.34 & 0.35 & 0.34 \\
Observations & 135,468 & 135,468 & 135,468 \\
\hline
\end{tabular}

Note: All the variables described in the Appendix were included, but are not reported to save space. All coefficients statistically significant at $1 \%$ level. 


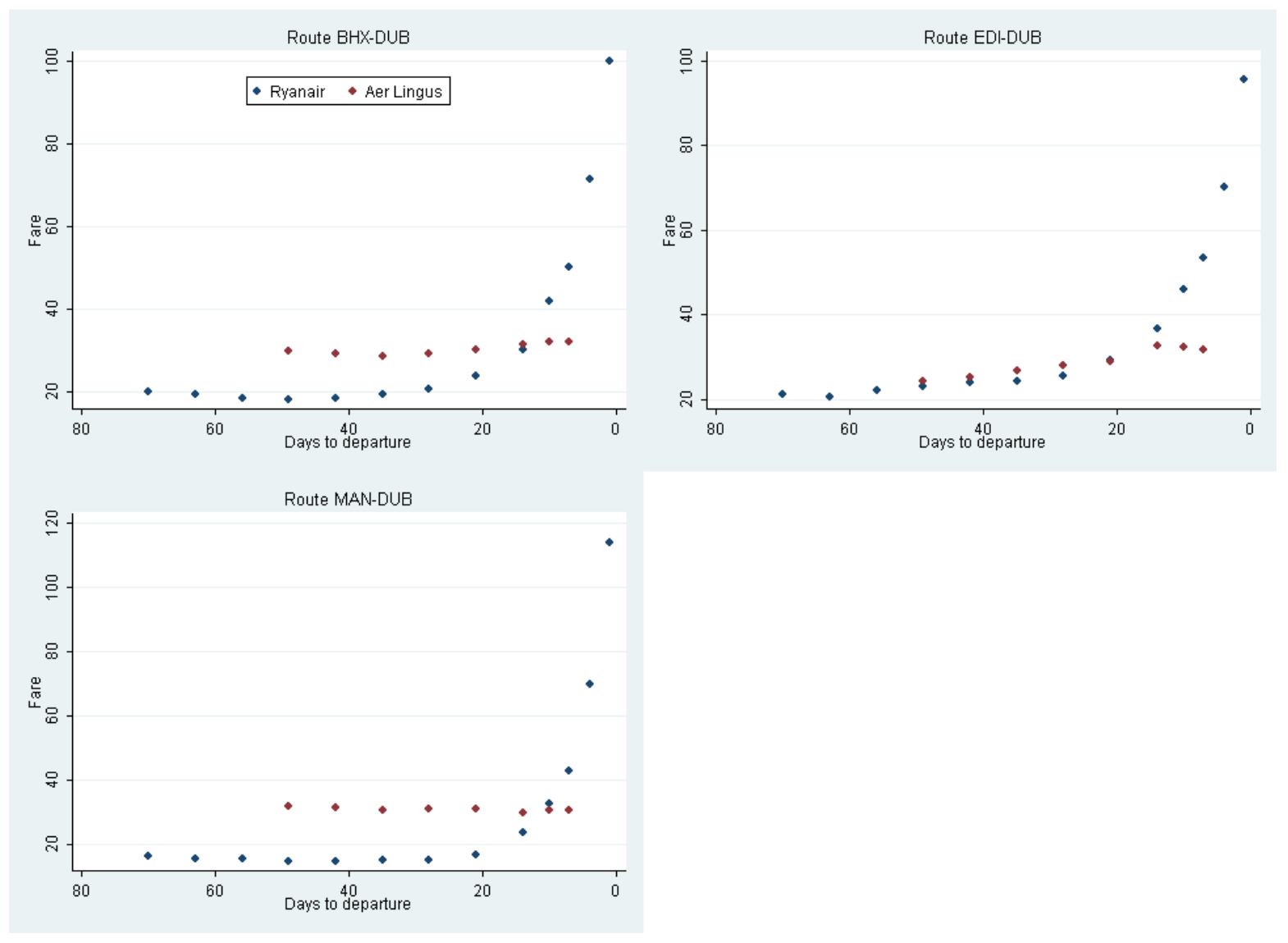

Figure 1: Fares temporal profile in overlapping routes. 